\title{
The Nature of the Business Group: Power, Relational Contracts and Scope
}

\author{
Raja Kali \\ Department of Economics \\ Sam M. Walton College of Business \\ University of Arkansas \\ Fayetteville, AR 72701 \\ Email:rkali@walton.uark.edu
}

Keywords: business group, boundaries of the firm, scope, scale, integration, explicit and implicit contracts.

JEL Classification: L22, L14, M13, D23 


\begin{abstract}
We propose a framework for understanding the business group, a hybrid organizational form that occupies the middle ground between firm and market and is a prominent feature of emerging economies. These organizations are characterized by varying levels of diversification and integration. We provide an explanation for the covariation, both positive and negative, in the scope, scale and strength of integration of business groups. This notion of integration embodies the degree of tightness in the ties that connect disparate subsidiary activities to the core of the business group, and is, we believe, novel to the theory of the firm. We also suggest the framework may be useful for understanding internal organizational hierarchy and multiproduct firms.
\end{abstract}




\section{Introduction}

What determines the boundaries of the firm? Coase's (1937) pathbreaking question has recently come into sharp focus in light of the unprecedented levels of mergers and acquisition activity in the past decade, together with an increased appreciation that the organizational landscape of many emerging economies is rife with forms, such as business groups and business networks, that are difficult to classify in standard ways as either firms or markets. Considering the ubiquity of these hybrid forms of organization that occupy the middle-ground between firms and markets, and their obvious relevance for the answer to Coase's question, it is surprising that the literature on industrial organization has paid so little attention to them $^{1}$. Our objective is to provide insight into the answer by turning attention to business groups.

What is a business group? Granovetter's (1995) suggestion that a "business group is a collection of firms bound together in some formal and/or informal ways," with the emphasis on "...an intermediate level of binding — excluding, on the one hand, a set of firms bound merely by short-term strategic alliances and, on the other, a set of firms legally consolidated into a single one," captures the essence of the form while ignoring the ways in which business groups differ within and across countries. A key dimension along which business groups vary is the degree of formality in linkages between the constituent firms and the core firm (see Granovetter, 1995 and Khanna and Rivkin, 2000). The ties that bind firms range from formal arms-length legal contracts to relational contracts grounded in family, ethnicity, society, religion and region. This variation in the strength of ties is an important component of the framework we propose here. We provide an explanation for the covariation - both positive and negative - between the scale and scope of a business group and the strength of the ties that bind the subsidiary firms to the core firm. This emphasis on the strength of integration $^{2}$ is, we believe a novel departure from the all-or-nothing binary approach to

\footnotetext{
${ }^{1}$ Business groups are a feature of the organizational landscape in many developing countries. Such groups dominate private-sector industrial activity in economies such as Brazil, Chile, Hong Kong, India, Indonesia, Malaysia, Pakistan, South Africa, South Korea and Taiwan, among others. See Ghemawat and Khanna (1998) for extensive multi-country references.

${ }^{2}$ We have decided to adopt the terminology of strength of integration as opposed to degree of integration because degree of integration is often used to connote how vertically integrated a firm is with regard to inputs
} 
integration that has largely dominated the literature on the theory of the firm.

Following Demsetz' (1993) interpretation of Coase we consider relational contracts to be more firm-like and formal arms-length contracts to be more market-like. Consequently we associate relational contracts with stronger ties and formal arms-length contracts with weaker ties. We believe this is consistent with the extensive literature on the theory of the firm that emphasizes incentives within the organization being less market-like than those across organizations $^{3}$.

The starting point for our theory is the notion that at the root of many economic enterprises is an entrepreneur with a unique critical resource that is an essential component in a wide variety of activities. Control of this resource is the source of power for the entrepreneur in his relationships with other firms. Examples could be ownership of critical raw materials, access to restricted licenses, privileged access to the seat of political power, a reputation for superior quality, or superior technological capability. Ownership of the critical resource enables the entrepreneur to expand into different product areas by establishing relationships with other firms whose capabilities are situated in these areas. The location of the entrepreneur with the critical resource is what we refer to as the "core" of the business group.

Our model thus grafts the notion of core competence ${ }^{4}$ onto Baker, Gibbons and Murphy's (1994) repeated game model of explicit and implicit contracting. As in their model, explicit contracts are associated with a noisy objective performance measure, and relational contracts are associated with a less noisy subjective performance measure. However, we introduce the idea that activities are more costly to measure subjectively the farther they are located from the core. This enables us to focus on different issues than them. Our contribution lies in relating the comparative static analyses of changes in the noise of the objective performance measure to the boundaries of the organization and its strength of integration. In the context of business groups in emerging economies, the level of noise in objective performance measures and outputs. This is quite a different focus from the one we have here.

${ }^{3}$ Simon (1951) argued that relational contracts were at the center of employment relations, and Williamson (1975) argued that relational contracts were the key differentiator of firms from markets.

${ }^{4}$ This follows the usage in the management literature on the core competence of a firm such as in Prahalad and Hamel (1990), that is in turn based on the resource-based view of the firm (Penrose, 1959). We explain this in more detail below. 
can be interpreted as being correlated with the under-development of legal and financial infrastructure.

The farther away subsidiary activities are from the location of the core entrepreneur, the more costly it is to use subjective relational contracts. We thus rely on a spatial metaphor to represent the idea that it is easier for the entrepreneur to obtain subjective data on activities or individuals who are less disparate from or "closer" to the core ${ }^{5}$. The quality of the subjective performance assessments is assumed not to degenerate with distance from the core, because these measures are based on kinship or social ties commonly assumed to have good informational capabilities ${ }^{6}$. For the same reason, relational contracts are assumed to be less "noisy" instruments of performance evaluation than arms-length contracts. The objective performance measure is noisy, but does not vary with distance from the core. In the model, the entrepreneur chooses the scope (distance from the core), which in turn determines the scale (number of subsidiary activities) and the mix of arms-length and relational contracts between himself and the subsidiary firm (the strength of integration) so as to maximize net returns.

We begin our analysis with a baseline environment in which institutions are so underdeveloped that no objective performance measures are feasible. This implies that arms-length contracts are not available. In such a situation the scale and scope of the organization will be based on a straightforward calculation of the distance from the core at which relational contracting breaks down. If outside opportunities improve for the subsidiary firms, it becomes more difficult to sustain the bonds of relational contracting and the scope and scale of the organization shrinks and could conceivably collapse to a point (or "black hole"). This kind of situation is similar to the "disorganization" interpretation of the output collapse that has been observed in Russia and several other transition economies following the collapse of socialist methods of economic organization (see Blanchard and Kremer, 1997).

\footnotetext{
${ }^{5}$ This seems appropriate given the importance of networks, connections and ties of kinship in surmounting informational problems. See, for example Alesina and La Ferrara (2000), Rachel Kranton (1996) and Raja Kali (1999). An example of a model that uses the 'distance' metaphor for coordination costs is by Alesina and Spolaore (1997).

${ }^{6}$ See the extensive literature on community based lending (for example Ghatak, 2000) or business network finance (see McMillan and Woodruff 1999 a, b) for further justification.
} 
We then consider situations where some objective performance measures are feasible. Starting from a situation where the distortion in the objective performance measure is sufficiently high, which could be due to poor institutional development as alluded to earlier, a decrease in the noise causes relational contracts to become stronger and the scope and scale of the organization expands. This expansion in scale, scope and strength of relational ties continues until the distortion in the objective measure is reduced to the level at which explicit arms-length contracting becomes a viable fallback option. After this point, the scope and scale of the organization abruptly start moving in the opposite direction and become smaller, accompanied by a decrease in the strength of ties as the distortion in the objective measure decreases. These results are consistent with a recent study by Khanna and Palepu (1999a) that looks at India and Chile before and after liberalization and finds an increase in group scope, an increase in the strength of social and economic ties that bind together group firms, and evidence of improvement in profitability and market value of group affiliates. A second paper (Khanna and Palepu, 1999c) tracks business groups in Chile over a longer term, during which institutions improved and market intermediaries developed, and finds evidence for a decrease in scope, scale and strength of $\operatorname{ties}^{7}$.

Coase's insight that the choice between locating transactions within a firm and in the market depends on the transaction costs of each form of economic organization continues to influence the recent resurgence of interest in the boundaries of the firm ${ }^{8}$. The work of Williamson $(1975,1985)$, by identifying more precisely the nature and sources of transaction costs, has enabled the focus of attention to shift from the coordination problems originally emphasized by Coase toward the role of firm boundaries in providing incentives. The research program that dominated the question in the last decade, the property rights approach, pioneered by Grossman and Hart (1986) and Hart and Moore (1990), has most recently led to a broader view of the firm as a complex mechanism for coordinating and motivating individual activities (Holmstrom and Milgrom, 1994; Rajan and Zingales, 1998, 2001; Holmstrom 1999). This most recent strand of research is characterized by a reassertion of the importance of measurement costs of the kind stressed by Alchian and Demsetz (1972), and a recognition that ownership of critical resources, reminiscent of the resource-based view of the firm (see

\footnotetext{
${ }^{7}$ We discuss empirical motivation in greater detail in the next section.

${ }^{8}$ See Holmstrom and Roberts, (1998) for an excellent survey.
} 
Penrose, 1959; Wernerfelt, 1984 and Montgomery, 1994), is an important source of power for the entrepreneur. Measurement problems and ownership of critical resources are both important ingredients of the framework we present here.

We believe this paper contributes to the current research program in organizational economics that emphasizes the importance of contractual governance for the theory of the firm (see Baker, Gibbons and Murphy 1999, 2001; Zingales, 2000). In a number of recent contributions, Baker, Gibbons and Murphy $(1999,2001)$ emphasize the role of relational contracts in understanding relationships between and within firms. They suggest that organizational design (integration versus distintegration) is often tailored in response to the best feasible relational contract. By extending the relational contracting paradigm into a different area this paper could be viewed as a complementary effort.

Thus, while the initial motivation for this paper comes from trying to understand the hybrid organizational form of the business group that is prevalent in many emerging economies, we believe that the framework may also prove useful for the understanding of organizational phenomena in other contexts that share similar features. We therefore devote some space in section 5 to discussing two possible applications: internal organizational hierarchy and "corporate coherence" in diversified firms (see Teece et. al., 1994).

The rest of the paper is organized as follows. Section 2 of the paper provides a brief overview of some recent empirical literature on emerging economy business groups that is the primary motivation for the theoretical framework. Section 3 outlines the basic framework. Section 4 uses the framework to derive implications for scope, scale and strength of integration. In section 5 we suggest applications to the issue of scope in multiple product lines and internal organizational hierarchy. Section 6 concludes with caveats and a discussion of ways in which this research could proceed further.

\section{Business Groups}

Business groups are a prominent feature of the industrial organization of many emerging economies. Such groups dominate private-sector industrial activity in economies such as Brazil, Chile, Hong Kong, India, Indonesia, Malaysia, Pakistan, South Africa, South Korea and Taiwan (see Ghemawat and Khanna, 1998), and are characterized by diversification 
across a wide range of businesses ${ }^{9}$, and in many cases, familial control.

Our theory is premised on the idea that the core firm in the business group has privileged access to resources that are an important ingredient in a wide variety of subsidiary activities. Recent empirical research on business groups that spans a broad spectrum of emerging economies provides evidence that business group membership positively affects firm profitability and that privileged access to scarce and critical resources is an important driver of such agglomerations.

In order to study the relative performance of firms affiliated to business groups, in a recent paper Khanna and Rivkin (1999b) have gathered data from local sources on group affiliation and performance for firms in thirteen emerging economies. Using methodology that has been used extensively to examine firm performance in the US, in a series of withincountry estimations they look for fixed effects associated with business group membership after controlling for firm and industry-specific fixed effects. In nine out of the thirteen countries in their sample, the contribution of group membership to profitability is significant at the $1 \%$ level. In Argentina, this contribution is significant at the $5 \%$ level, whereas it is insignificant at conventional levels in Mexico, Peru and Turkey. These results can be interpreted as confirming that group membership explains a large and significant portion of the variation in firm performance. Furthermore, Khanna and Rivkin find that of the seven countries where the greatest number of groups are observed, the mean group coefficient is positive and statistically significantly different from zero in India, Indonesia and Taiwan, and statistically indistinguishable from zero in the others (Brazil, Chile, South Korea, Thailand). When they include the countries in which a small number of groups (12 or less) are observed, they find that the mean group coefficient is positive in seven of the 13 countries. Across all the countries in the exercise, there is only one, Argentina, in which the mean group effect is statistically significantly negative.

A similar picture emerges from other empirical studies. Keister (1998) shows that the formation of groups in China, modeled along the lines of Japanese keiretsu and the Korean

\footnotetext{
${ }^{9}$ For example, the House of Tata in India has interests in steel, watches, detergents, tea, automobiles, and computer software. Grupo Luksic of Chile has interests in banks, hotels, mining, beer and pasta. Grupo Carso of Mexico has firms in telecoms, internet services, retail and finance. See "When eight arms are better than one," The Economist, Sept. 12, 1998, pp. 67-68.
} 
chaebol improved firm level financial productivity in the later 1980s. Perotti and Gelfer (1999) find that group firms in Russia have higher values of Tobin's q than comparable unaffiliated firms.

On the question of access to resources, a recent study by Chang and Hong (2000) uses longitudinal data on 30 Korean chaebols from 1985-96 to find support for the resource-based view that business groups arise in order to share tangible resources such as capital and raw materials, and intangible resources such as reputation and R\&D. A recent study by Guillen (2000) also uses longitudinal data on business groups, from South Korea, Spain and Argentina to examine their ability to use proprietary resources and coordination skills to outperform non-business group firms, finding substantial support for the resource-based view.

Guillen also finds from a comparative longitudinal analysis of the top 100 nonfinancial firms in these three countries that business groups expand over time in countries following an asymmetric trade and investment policy that hinders foreign investment and development of market intermediaries. However, the advantage of groups is eroded as the asymmetric policy is dismantled. In a similar vein, a recent study by Khanna and Palepu (1999a) that looks at India and Chile before and after deregulation in primary markets finds an increase in group scope, strengthened social and economic ties among affiliated firms, and evidence of improved profitability and market value of affiliates. In a separate study that tracks the performance of business groups in Chile over the long run (Khanna and Palepu, 1999c), from 1988-1996, they find that the benefits of group affiliation atrophy over time. They suggest that the evolution of institutional context — the development of market intermediaries that reduce the extent of informational and agency problems - is an important element in this gradual unraveling of business groups.

This is consistent with the implications of the framework that suggest that when informational and associated agency problems are serious, an improvement along these dimensions will be initially accompanied by an expansion in the scale and scope of business groups. However, if informational problems continue to decline, enabling better objective measures, a threshold level is crossed beyond which business groups start to unravel, giving way to arms-length contracting between firms. 


\section{The Framework}

Our framework combines the resource-based view of the firm ${ }^{10}$ with the agency model of Baker, Gibbons and Murphy (1994).

\section{Technology}

An entrepreneur possesses a unique critical resource that he wants to exploit. This resource can be combined with $n$ other activities, corresponding to $n$ other agents or firms in order to produce final output. The entrepreneur has to give the other agents access to the critical resource for them to produce effectively (as in Rajan \& Zingales, 2000).

The specialized subsidiary activities (and corresponding agents) ${ }^{11}$ are uniformly distributed $^{12}$ with density $\delta$ along a line of infinite length with the origin being the location of the entrepreneur with the critical resource. The location of the entrepreneur in product space could be thought of as the "core" of the business group. The distance of an agent from the core, which we call $x$, is important because the cost of obtaining a subjective evaluation on the performance of the agent is proportional to the distance from the core. The objective performance measure does not depend on distance from the core (more on these measures below).

If the distance from the core of the most disparate activity that is part of the business group is $\bar{x}^{13}$ (which we refer to as the boundary of the business group), the number of subsidiary activities between the core and the boundary, $N=\delta \bar{x}$ is what we refer to as the scale of the business group. Though this interpretation of scale is mechanistic, what we have in mind is the notion that different product lines (or product "directions") may vary in potential for subsidiary activities. This could be captured by variation in the exogenous density parameter $\delta$. We discuss this in more detail in Section 5.

Since we are not concerned with the technological limits to organizational size, the production function is assumed to be linear in the number of subsidiary firms associated with

\footnotetext{
${ }^{10}$ See Montgomery, 1994, for an overview.

${ }^{11}$ Since the subsidiary firms are the agents of the entrepreneur controlling the critical resource, we use the words agent and subsidiary firm interchangeably.

${ }^{12}$ We assume a uniform distribution solely for tractability. The general idea is just that subsidiary activities are distributed along a product line with some density. See Section 5 for further discussion.

${ }^{13}$ We derive $\bar{x}$ in the next section.
} 
the core entrepreneur. If $n$ subsidiary firms contributed perfectly to final output, together with the entrepreneur the output of the business group would be $n+1$.

All prices are measured in units of output.

\section{$\underline{\text { Measurement }}$}

The subsidiary firms can be bound to the core entrepreneur through relational and armslength ties. These linkages differ with regard to how the entrepreneur can use them to measure and reward performance of the subsidiary firms. There are two types of performance measures that the entrepreneur can use to evaluate subsidiary firms, a subjective measure and an objective measure. The reward tied to the subjective measure is the relational contract while the reward tied to the objective measure is the arms-length contract.

The arms-length contract between the entrepreneur and the subsidiary firm is third-party enforceable. The relational contract needs to be self-enforcing through the reputational concerns of the entrepreneur. We therefore consider a repeated game between the entrepreneur who possesses the critical resource and $n$ independent subsidiary firms.

$\underline{\text { Subjective measure }}$

In each period the subsidiary firm chooses the level of unobservable effort $a$, which stochastically determines the firm's contribution to business group value $y$. We assume that $y$ equals either zero or one and $\operatorname{Prob}[y=1 \mid a]=a$, where $a \in[0,1]$. Because of the complex nature of the firm's activity, we assume contribution $y$ cannot be objectively measured. But it can be subjectively assessed. This subjective assessment forms the basis for the relational link between the core entrepreneur and subsidiary firm.

\section{Objective measure}

The subsidiary firm's action also stochastically affects a second performance measure $p$ which also equals either zero or one. $p$ can be objectively measured, and so can be the basis of an arms-length contract.

However, $p$ is a noisy measure of the firm's contribution to business group value. Before choosing effort, the firm receives private information (denoted by $\mu>0$ ) about the separate effects of effort on $y$ and $p . \operatorname{Prob}[p=1]=\mu a$, (we assume $\mu a<1$ ). Given $\mu$ and $a$, the events that $y=1$ and that $p=1$ are independent ${ }^{14}$. To minimize notation, assume $E(\mu)=1$. The

\footnotetext{
${ }^{14}$ High values of $\mu$ (say around one) are situations when actions increase both $y$ and $p$, small values of $\mu$ (say
} 
performance measure $p$ is thus an unbiased measure of contribution $y$.

\section{Strength of Ties}

A subsidiary firm is linked to the core entrepreneur through relational and arms-length contracts. The arms-length-contract stipulates a transfer of $\beta$ from the entrepreneur when the objective measure is $p=1$. Under the relational contract the understanding is that the subsidiary is paid $b$ when the subjective assessment is $y=1$. These two kinds of contracts are used by the core entrepreneur to motivate effort on the part of the subsidiary firms. In addition, a lump-sum fee of $s$ is paid to ensure the participation of the subsidiary firms in the business group.

As described earlier, we associate higher values of the relational component $(b)$ with stronger ties between the core and the subsidiary agent, in accordance with the notion that this is a more "firm-like" arrangement. We interpret higher powered arms-length contracts $(\beta)$ as being a more "market-like" arrangement.

\section{Timing of Events}

(1) The entrepreneur chooses the scope of the business group by determining the distance $x$ from the core of the most disparate activity that will be the boundary of the group. This in turn determines the number of agents $N=\delta \bar{x}$ in the business group. $N$ is what we refer to as the scale of the business group.

(2) The entrepreneur proposes a bundle of relational and arms-length contracts $(s, b, \beta)$ to the subsidiary firms at different locations.

(3) Each subsidiary firm binds itself to the core entrepreneur by accepting the previous bundle of contracts or rejects it in favor of an alternative opportunity with reservation payoff $w$.

(4) If the firm accepts, then the firm observes $\mu$ and chooses effort $a$ at cost $c(a)=\gamma a^{2}$. The entrepreneur does not observe $\mu$ or the firm's effort.

(5) The core entrepreneur observes the realization of the subsidiary firm's subjective contribution $y$ by incurring a cost $t x$, where $x$ is the distance of the subsidiary firm from the entrepreneurs's location and $t \geq 0$ is the per unit distance cost of gathering the subjective around zero) are situations when actions increase $y$ but not $p$, and values of $\mu$ greater than one are situations when small actions increase $p$ but not $y$. 
assessment. The subsidiary firm's observation of $y$ is costless.

The entrepreneur and the subsidiary firm (and, if necessary, a court) costlessly observe the realization of the objective performance measure.

(6) If $p=1$, then the entrepreneur pays the quantity $\beta$ dictated by the arms-length contract. If $y=1$, then the entrepreneur chooses whether to pay the subsidiary firm $b$ as specified by the relational contract.

\section{Scope, Scale and Strength of Integration}

Given a relational contract $b$ and an arms-length contract $\beta$, if the subsidiary firm believes the entrepreneur will honor the relational contract, then the firm's problem after observing the realization of $\mu$ is

$$
\operatorname{Max}_{a} s+a b+\mu a \beta-\gamma a^{2}
$$

which yields the optimal effort

$$
a^{*}(\mu, b, \beta)=\frac{(b+\mu \beta)}{2 \gamma}
$$

The subsidiary firm will choose to work for the entrepreneur if his expected payoff (before observing $\mu$ ) exceeds that of the alternative opportunity, i.e., the individual rationality/participation constraint is satisfied,

$$
\left.E_{\mu}\left[s+a^{*}(\mu, b, \beta) b+\mu a^{*}(\mu, b, \beta) \beta\right)-\gamma a^{*}(\mu, b, \beta)^{2}\right] \geq w
$$

Suppose now the subsidiary firm is located at a distance $x$ from the core. The entrepreneur's expected profit per period from his relationship with this subsidiary firm is,

$$
E_{\mu}\left[a^{*}(\mu, b, \beta)-\left(s+a^{*}(\mu, b, \beta) b+\mu a^{*}(\mu, b, \beta) \beta\right)\right]-t x
$$

The base fee $s$ will be the lowest quantity satisfying the participation constraint. Substituting this into the expected profit above yields the entrepreneur's expected profit per period as a function of the relational payment $b$, the arms-length component $\beta$ and the distance from the core $x$, which we denote $V(b, \beta, x)$. 


$$
V(b, \beta, x) \equiv E_{\mu}\left[a^{*}(\mu, b, \beta)-\gamma a^{*}(\mu, b, \beta)^{2}-w-t x\right]
$$

We consider two separate cases. First, we consider a situation where arms-length contracts are not an option. While this is of course an extreme situation and is meant to serve mainly as a benchmark, it can be motivated by thinking about an economy where there is almost no institutional infrastructure, or the existing institutions are extremely corrupt or unreliable - to the extent that they are worthless in supporting arms-length contracting.

\subsection{Case (A): Relational Contracts}

Assume the agent is located at distance $x$ from the entrepreneur.

The incentives provided by the relational contract $(s, b)$ depend on whether the subsidiary firm trusts the core entrepreneur to honor its relational commitment to pay the amount $b$ after observing performance $y=1$. If the firm believes the entrepreneur will not renege

on the relational payment, the firm's effort decision is $a^{*}(\mu, b, \beta)=\frac{b}{2 \gamma}$. The entrepreneur's expected profit per period is then,

$$
V(b, x) \equiv a^{*}(b)-\gamma a^{*}(b)^{2}-w-t x=\frac{b}{2 \gamma}-\frac{b^{2}}{4 \gamma}-w-t x
$$

As mentioned earlier, to formalize the notion of trust in enforcing relational contracts we consider an infinitely repeated relationship. We consider equilibria in which both parties play trigger strategies such that any betrayal destroys the relationship forever. The parties begin by cooperating and then continue cooperating unless one side defects, in which case they refuse to cooperate forever after. If the subsidiary's contribution is $y=1$ the entrepreneur has to decide whether to pay the relational component $b$. The entrepreneur should pay if and only if the present value of the expected profit beginning next period exceeds the size of the payment: $V(b, x) \geq b r$.

The optimal relational contract sets $b$ to maximize expected profit per period $V(b, x)$ subject to this reneging constraint. This optimization yields the function $b^{*}(r, w, t, x)$, that is decreasing in its parameters. The derivation of this function has been placed in the appendix. 
Consequently, for given values of the other parameters, the distance from the core beyond which relational contracting will break down can be obtained by solving for the value of $x$ (call this $\bar{x}$ ) at which $b^{*}(r, w, t ; \bar{x})=0$. Another way to frame this is to say that the set of optimal relational contracts $\left\{b^{*}(x) \mid V(b, x) \geq b r\right\}$ is empty for $x>\bar{x}$.

Thus if the subsidiary firms are uniformly distributed with density $\delta$ along a line with it's origin at the core (i.e., the location of the entrepreneur), the boundary of the business group will be the firm (and corresponding activity) located at $\bar{x}$. We could then say that the scale of the business group will be $N=\delta \bar{x}$.

\section{$\underline{\text { Discussion }}$}

We can see that if the per-unit-distance verification expenditure $t$ falls, $\bar{x}$ rises. Since $\bar{x}$ is the distance of the boundary agent from the core, we could interpret it as the scope of the organization. $N$ is the scale of the business group in terms of number of associated subsidiary firms. Notice that if scope increases, then scale also increases, but an increase in scale need not be accompanied by an increase in scope. For instance, if $\delta$ is high and $\bar{x}$ is low (which may happen if $t$ or $w$ are high), we can have large scale but narrow scope. Conversely, if $\delta$ is low and $\bar{x}$ is high (if $t$ or $w$ are low), we can have small scale but broad scope. And if both $\delta$ and $\bar{x}$ are high, we can have large scale and broad scope.

As outside opportunities improve (an increase in $w$ ), the present value of the ongoing relationship falls and so the relational contract bonus $b$ falls. This in turn causes the scope $\bar{x}$ to fall. In other words, an improvement in outside options is accompanied by a breakdown in the extent of relational contracting and a reduction in the scope and scale of the organization. If the improvement in outside options is large enough the organization may collapse altogether ending up as a point or "black hole." If this happens on an economy-wide scale, output for the entire economy may fall dramatically. This kind of situation is similar to the "disorganization" interpretation of the output collapse that has been observed in Russia and several other transition economies following the collapse of socialist methods of economic organization (see Blanchard and Kremer, 1997).

A recent paper by Recanatini and Ryterman (2000) continues the inquiry by noting that in the aftermath of the initial sharp output collapse, organizations which they term business associations have emerged in many parts of Russia. Using a new firm-level data set they 
provide evidence that these organizations arrested the output decline in regions where they emerged. Using a probit model they find that belonging to a business association reduces the likelihood of an output decline by as much as $47 \%$. They also find evidence that the formation of such an association is affected by regional characteristics. Membership in an association is more likely for firms that were formerly under the umbrella of the same Soviet planning ministry, because of prior relationships and contacts that existed ${ }^{15}$, and for firms that are closer in terms of geographic distance. In terms of our framework these factors seem clear proxies for the limits of relational contracting.

\subsection{Case (B): Relational and Arms-Length contracts}

We now consider the combination of an arms-length contract based on an objective measure with a relational contract based on a subjective assessment. We assume that the subjective assessment is noncontractible but otherwise perfect ${ }^{16}$.

Now the expected profit from honoring the contract is not $V(b, x)$ from Case (A) but $V(b, \beta, x)$. Also, when arms-length contracts are available, they are available both before and after the entrepreneur reneges. We assume that if the entrepreneur were to renege, then the subsidiary firm would refuse to participate in any future relational contracts but would be willing to consider arms-length contracts and would accept an arms-length contract if it were sufficiently attractive. In order to derive the reneging constraint in this case we therefore need to characterize the payoff when only arms-length contracts are used.

From equation (2), the subsidiary's optimal action will then be $a^{*}(\mu, \beta)=\frac{\mu \beta}{2 \gamma}$. The optimal fallback contract for the entrepreneur sets $\beta$ at the value that maximizes the expected profit per period,

$$
\max _{\beta} E_{\mu}\left[a^{*}(\mu, \beta)-\gamma a^{*}(\mu, \beta)^{2}-w\right]
$$

Solving the first-order condition implies that the optimal arms-length contract bonus in

\footnotetext{
${ }^{15}$ Which they refer to as the Soviet legacy effect.

${ }^{16}$ We could allow the subjective assessment to be imperfect as well, without altering the qualitative results, so long as the subjective measure is less noisy than the objective measure. See Baker, Gibbons and Murphy, (1994) section III.B for an analysis of imperfect subjective assessments.
} 
the fallback situation is

$$
\beta^{*}=\frac{E_{\mu}[\mu]}{E_{\mu}\left[\mu^{2}\right]}=\frac{1}{1+\operatorname{var}(\mu)}
$$

and,

$$
V\left(\beta^{*}\right)=\frac{1}{4 \gamma 1+\operatorname{var}(\mu)}-w .
$$

In the absence of relational contracts, the expected profit per period from the optimal contract is $V\left(\beta^{*}\right)$ as defined in (9), which can be positive or negative depending on the firm's opportunity cost $w$ and the level of noise in the objective performance measure, $\operatorname{var}(\mu)$. The fall back position for an entrepreneur reneging on relational contracts is $V\left(\beta^{*}\right)$. So we consider two subcases, when $V\left(\beta^{*}\right)>0$ and $V\left(\beta^{*}\right)<0$.

Case B.1: $V\left(\beta^{*}\right)>0$

The reneging constraint is now,

$$
V(b, \beta, x)-V\left(\beta^{*}\right) \geq r b
$$

If this constraint is satisfied, the subsidiary's effort decision is $a^{*}(\mu, b, \beta)$ as in $(2)$. The optimal contract sets $b$ and $\beta$ to maximize expected profit $V(b, \beta, x)$ as in (5) subject to this reneging constraint. Going through this constrained optimization problem yields the optimal $\beta$ for a given value of $b$,

$$
\beta^{* *}(b)=\frac{(1-b)}{1+\operatorname{var}(\mu)}=(1-b) \beta^{*}
$$

For parameter values such that the first-best relational contract $b^{* *}=1$ is not feasible, the optimal $b^{* *}$ is determined by substituting $\beta^{* *}(b)$ into the reneging constraint, which becomes,

$$
V\left(b, \beta^{* *}(b), x\right)-V\left(\beta^{*}\right)=\frac{b(2-b)}{4 \gamma} \cdot \frac{\operatorname{var}(\mu)}{1+\operatorname{var}(\mu)}-t x \geq r b
$$

The optimal relational-contract bonus $b^{* *}$ is the largest value of $b$ solving this constraint. Equation (12) yields a quadratic equation in $b$ from which we can obtain the function $b^{* *}(r, x, t, \operatorname{var}(\mu))$. The derivation of $b^{* *}$ is methodologically similar to that of section 4.1 can be found in the appendix. As in 4.1 the function is decreasing in the first three arguments. In addition it is increasing in the noise parameter $\operatorname{var}(\mu)$. 
For given values of the other parameters, the distance from the core beyond which relational contracting will break down can be obtained by solving for the value of $x$ (call this $\overline{\bar{x}})$ at which $b^{* *}(r, t, \operatorname{var}(\mu) ; \overline{\bar{x}})=0$. This implies that the set of optimal relational contracts $\left\{b^{*}(x) \mid V(b, x) \geq b r\right\}$ is empty for $x>\overline{\bar{x}}$.

From this we obtain that $\bar{x}=0$ when $\operatorname{var}(\mu)<\frac{2 \gamma r}{1-2 \gamma r}$. That is, if objective performance measures are sufficiently reliable, relational contracts are not feasible. Consequently scope, and hence scale of the business group will be very small. Economic organization takes the form of arms-length contracting through purely explicit contracts.

So long as $\operatorname{var}(\mu) \geq \frac{2 \gamma r}{1-2 \gamma r}$ subjective contracts will be feasible and scope and scale will be positive. Scope increases as the objective performance measure becomes more noisy, i.e., $\bar{x}$ increases as $\operatorname{var}(\mu)$ increases. Also, $b^{* *}$ rises and $\beta^{* *}$ falls. We could interpret this as saying that as the objective performance measure becomes more noisy, scope and scale expands and relational ties become stronger. Relational and arms-length contracts are substitutes in this situation.

Case B.2: $V\left(\beta^{*}\right)<0$

This situation can arise when the incentive distortions in the objective performance measure are sufficiently high. In this case the fallback position after reneging on a relational contract is to shut down The reneging constraint is now,

$$
V(b, \beta, x) \geq r b
$$

$$
\begin{aligned}
& \text { or, } E_{\mu}\left[a^{*}(\mu, b, \beta)-\gamma a^{*}(\mu, b, \beta)^{2}-w-t x\right] \geq r b \\
& \text { or, } \frac{1}{4 \gamma}\left[2(b+\beta-b \beta)-b^{2}-\beta^{2}(1+\operatorname{var}(\mu))\right]-w-t x \geq r b .
\end{aligned}
$$

The first order conditions are the same as above and we can then write the reneging constraint as,

$$
V\left(b, \beta^{* *}(b)\right)=\frac{1}{4 \gamma}\left[2 b k-b^{2} k+1-k\right]-w-t x \geq r b \text { where } k=\frac{\operatorname{var}(\mu)}{1+\operatorname{var}(\mu)}
$$

Again, the optimal relational-contract bonus $b_{j}^{* *}$ is the largest value of $b_{j}$ solving this constraint, which is a quadratic equation from which we can obtain the function $b^{* *}(r, x, t, \operatorname{var}(\mu))$. The derivation is contained in the appendix. As in the previous case the function is decreasing in the first three arguments. For given values of the other parameters, the distance from the core beyond which relational contracting will break down can be obtained by solving 
for the value of $x$ (call this $\overline{\bar{x}})$ at which $b^{* *}(r, t, \operatorname{var}(\mu) ; \overline{\bar{x}})=0$. However, in contrast to the previous case, it is decreasing in the noise parameter $\operatorname{var}(\mu)$. In this case if $\operatorname{var}(\mu)$ increases, scope falls. The effect of a change in $\operatorname{var}(\mu)$ on $\beta^{* *}$ is ambiguous.

\section{Discussion}

In contrast to case B.1, in this situation, starting from a situation where the noise in the objective performance measure is sufficiently high, a decrease in the noise causes relational contracts to become stronger and the scope and size of the business group expands. What happens in this case is that though the objective contract by itself is not a viable fallback, it's improvement (through the decline in the noise) enhances the effectiveness of the relational contract by increasing the value of the ongoing relationship between the entrepreneur and the agent. In the previous case however, a decline in the noise causes relational contracts to become weaker; scope and scale falls.

Combining the results of cases B.1 and B.2, we could summarize in the following manner: Starting from a very high level of noise (very poor institutional development), if the noise decreases, scale expands and relational contracts become stronger. The strength of integration increases. This continues until we reach the point where the noise is small enough that the fallback reneging option of purely objective contracts $V\left(\beta^{*}\right)$, switches from being negative to positive. After this point if the noise continues to decline, scope falls and relational contracts become weaker, implying a decline in the strength of integration. This pattern of covariation in the scope, scale and strength of integration is consistent with the stylized facts on co-evolution of business groups and institutional context described earlier.

\section{Applications}

\subsection{Internal Organizational Hierarchy}

Suppose we now relax the assumption that the difficulty of measuring performance objectively is the same for all activities. If we rank activities within the firm in terms of complexity, where high complexity corresponds to high level of noise in the objective measure, then we can apply the preceding theory to cast light on the hierarchical shape of an organization. If we suppose that each agent can in turn have other agents to help him or her, i.e., a layer of 


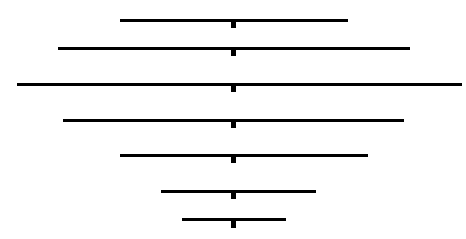

Figure 1:

hierarchy, and if we assume that the complexity of subordinate activities is directly related to the complexity of the principal activity, then our framework implies that the size of a hierarchical layer depends on the complexity of the activity at the corresponding level of the organization. The overall hierarchical shape of the organization then depends on how the complexity of activities is distributed through the organization. For example, if we make the standard assumption that more complex activities are higher-up in the organization, and that as we move down the organization activities become less complex and more routine, then following the analysis of section 4.2, starting from the top-most echelons of the firm and moving to the bottom, internal hierarchies will first grow larger as we move to middle management, and then diminish in size as we move down the firm to less complex/more routine activities. If we stack the hierarchical layers on top of each other this suggests an organizational shape such as in figure 1. It is easy to see that other shapes are also possible. For instance, if complexity within the firm falls off very sharply, the overall shape of the organization may be relatively flat.

We can compare this with the actual relationship between the span of control and hierarchical level within a large U.S. firm that is studied in detail by Baker, Gibbs and Holmstrom (1993, 1994), that we present in Figure 2. The layers of heirachy are scaled proportionately 


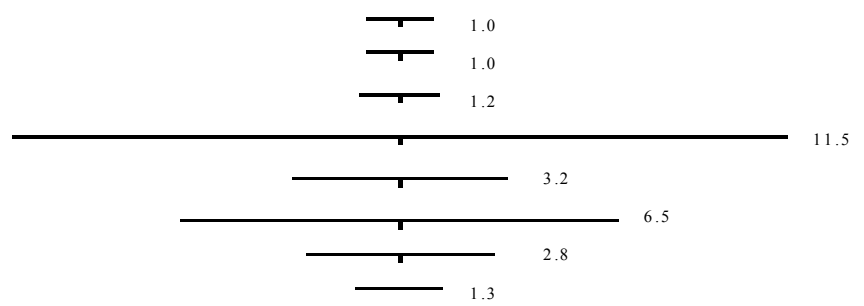

Figure 2:

and the numbers in parentheses are the span of control numbers reported in Baker, Gibbs and Holmstrom $(1993)^{17}$.

\section{$5.2 \quad$ Multiproduct Scope}

The preceding analysis has been based on expansion of activities along a single product line. But it is possible that the critical resource that is the source of the entrepreneur's power can be the basis for expansion into multiple product lines. The extent to which this is feasible depends importantly on the characteristics of the resource, that determine how "specific" or "general" it is ${ }^{18}$. In an abstract sense, we could consider an infinity of different directions into which a firm that possesses a critical resource could possibly expand. However, on account of the specificity of the resource only a small number of these potential opportunities are cost

\footnotetext{
${ }^{17}$ Span of control is the ratio of employees at the next lower level to those at that level. Figure 2 is constructed from data in Table 1, page 371.

${ }^{18}$ Montgomery and Wernerfelt (1988) use diversification and Tobin's q to find evidence for resources varying in specificity.
} 
effective. One way to think of this in terms of our framework is through the per-unit distance information cost parameter $t$. If we recognize that $t$ can vary across different product lines, most directions of diversification are precluded because of prohibitively high values of this parameter. A firm can thus diversify into only a finite number of directions.

The set of feasible directions into which a firm can diversify may also vary with regard to how dense or "fertile" each product direction is in terms of potential subsidiary activities. In terms of the framework this notion could be represented by heterogeneity in the density parameter $\delta$. If we allow for a finite number of different product directions that vary in their information costs and density of subsidiary activities, the framework may prove helpful in understanding the scale and scope of diversified firms.

For example, suppose that there are just two axes along which feasible productive activities are distributed. These axes represent different directions along which the entrepreneur can extend his critical capabilities by engaging in productive relationships with agents located on the axes. Each axis could differ in a number of ways. Because of the type of critical capability that is at the root of the entrepreneur's power, it could be that the capability is more easily extended along one axis rather than the other. This could be reflected in the smaller cost of obtaining the relational information along one axis than the other, say $t_{1}<$ $t_{2}$. Another difference could be that the density of potential subsidiary activities that can be combined with the critical capability is higher along one axis than the other, say $\delta_{1}<\delta_{2}$.

There are a couple of different cases to consider. First, we consider the case when the two axes are identical in all respects, and then the case of heterogeneity.

\section{Symmetric Axes}

In this case the extent of relational contracting will be the same in each direction. In each direction the analysis is similar to section 3 with $\bar{x}$ determining the scope in each direction. Since the density of activities is also identical, the scale of activities will be $N=\delta \bar{x}$ in each direction.

\section{Asymmetric Axes}

There are four possible cases, depending on whether $t_{1} \lessgtr t_{2}$ and $\delta_{1} \lessgtr \delta_{2}$. If $t_{1}<t_{2}$ then $\bar{x}_{1}>\bar{x}_{2}$. In this case the scope of activities in direction 1 will be broader than the scope of activities in direction 2. The scale of activities in direction $1, N_{1}$ will be higher than $N_{2}$ if 
$\delta_{1} \geq \delta_{2}$. But if $\delta_{1}<\delta_{2}$, then $N_{1}$ could be less than $N_{2}$ if $\delta_{1}$ is sufficiently small.

\section{Example: Sharp Corporation}

The diversified structure of Sharp Corporation, a well-known Japanese electronics conglomerate provides an example of this application ${ }^{19}$. During the 1970's Sharp centered its $\mathrm{R} \& \mathrm{D}$ resources on opto-semiconductors, which act as converters between light and electricity. This research thrust led to the establishment of superior technological capabilities in opto-electronics, culminating in breakthrough liquid crystal displays (LCD's) and laser diodes. LCD's became a critical component in nearly all of Sharp's products and the basis for Sharp's expansion into three different product lines:

- Consumer Electronics, with LCD flat screen TV's, LCD projectors and High Definition TV LCD's.

- Information Systems and Office Automation, with LCD Calculators, Electronic Organizers, Personal Computers and Cameras.

- Electronic Components and Device, with opto-magnetic disks, electro-luminiscent displays, laser diodes, solar cells and satellite components.

Atsushi Asada, a Sharp senior executive described Sharp's technology strategy as follows: "We invest in the technologies that will be the nucleus of the company in the future. Like a nucleus, such technologies should have an explosive power to multiply themselves across many products." The diversification of Sharp into different product lines is based on it's core capabilities in opto-electronics and liquid crystal displays.

\section{Conclusion}

The initial motivation for this paper comes from the desire to understand the boundaries of business groups, an organizational form that is ubiquitous in emerging economies, together with the variation in the strength of linkages that bind member firms to the core firm in such organizations. Since many emerging economies are characterized by inadequacies in

\footnotetext{
${ }^{19}$ This section draws on Noda, T. and Collis, D. J. (1995), "Sharp Corporation," Harvard Business School Publishing, 9-793-064.
} 
basic institutional infrastructure, such as a well developed legal and financial system ${ }^{20}$, informational and agency problems are likely to be serious. Reliable objective measures of performance will therefore be scarce. Consequently firms rely heavily on relational contracts that are based on subjective measures. When combined with the idea that the control of resources and capabilities that are critical ingredients in a wide range of productive activities may be in the hands of a select few entrepreneurs or families, we are able to understand the scope and scale of business groups and the strength of ties between the core and subsidiary firms. This perspective also provides us with a framework for understanding how the scope, scale and strength of integration of these entities covaries with changes in the institutional framework of emerging and transition economies.

A novel aspect of the paper are the implications with regard to the co-evolution of scale and scope with the strength of ties between member firms and the core. So far we do not know of research that has explicitly focussed on this dimension of integration, suggesting that this could be a fruitful avenue for further empirical work.

An important caveat to the present paper is of course the exogeneity of the change in institutional development. A recent paper by Grossman and Helpman (2001) develops a model of integration and outsourcing that identifies the feedback mechanisms by which firms' behavior determines market conditions, which in turn influence an individual firm's choice of organizational form. Combining the framework presented here with their ideas would be a future direction for this research.

We also feel that our theory also has the potential for application to broader issues in the economics of organization. It is difficult to understate that this suggests the need for careful empirical research in this area that takes into account the ideas forwarded here.

\footnotetext{
${ }^{20}$ The realization that markets do not function in a vacuum and that their efficient functioning depends on a (minimal) basic institutional infrastructure is arguably one of the important lessons from the recent experience of the transition economies. See Stiglitz (1999) for a more detailed discussion along these lines.
} 


\section{Appendix}

\section{Relational Contracts}

The optimal relational contract sets $b$ to maximize expected profit per period $V(b, x)$ subject to the reneging constraint $V(b, x) \geq b r$. As we can see from equation $(6), V(b, x)$ is quadratic in $b$. The reneging constraint therefore binds for values of the interest rate $r$ high enough that the first best $b$ is not attainable. The solution to this constrained optimization problem then becomes the highest value of $b$ satisfying the reneging constraint.

When the reneging constraint binds $V(b, x)-b r=0$. This implies,

$\frac{b}{2 \gamma}-\frac{b^{2}}{4 \gamma}-w-t x-b r=0$

or, $-b^{2}+2(1-2 \gamma r) b-4 \gamma(w+t x)=0$, which is a quadratic equation of the form,

$-b^{2}+Q b-R=0$, where $Q=2(1-2 \gamma r)$ and $R=4 \gamma(w+t x)$.

The solution of the optimization is the largest value of $b \in[0,1]$ that satisfies the quadratic equation. This is $b^{*}=\frac{Q+\left(Q^{2}-4 R\right)^{\frac{1}{2}}}{2}$.

Since $\frac{\partial Q}{\partial r}<$ and $\frac{\partial b^{*}}{\partial Q}>0$, by the chain-rule we have $\frac{\partial b^{*}}{\partial r}<0$. Also, since $R$ is increasing in all of its components and $\frac{\partial b^{*}}{\partial R}<0$, we have $\frac{\partial b^{*}}{\partial w}<0, \frac{\partial b^{*}}{\partial t}<0$ and $\frac{\partial b^{*}}{\partial x}<0$. We could summarize this analysis by writing $b^{*}(r, w, t, x)$, a function that is decreasing in its parameters.

\section{Relational and Arms-Length Contracts}

\section{Case B.1}

When the reneging constraint binds we have,

$V\left(b, \beta^{* *}(b), x\right)-V\left(\beta^{*}\right)-t x-r b=0$

or, $\frac{b(2-b)}{4 \gamma} \cdot \frac{\operatorname{var}(\mu)}{1+\operatorname{var}(\mu)}-t x-r b=0$

or, $-b^{2} k+(2 k-4 \gamma r) b-4 \gamma t x=0$

or, $-b^{2} k+Y b-Z=0$, where $k=\frac{\operatorname{var}(\mu)}{1+\operatorname{var}(\mu)}, Y=2 k-4 \gamma r$ and $Z=4 \gamma t x$.

The solution to the optimization is the largest value of $b \in[0,1]$ that satisfies the quadratic equation,

yielding $b^{* *}=\frac{Y+\left(Y^{2}-4 k Z\right)^{\frac{1}{2}}}{2 k}$.

$\frac{\partial b^{* *}}{\partial k}=\frac{1+\left(\left(Y^{2}-4 k Z\right)^{-\frac{1}{2}}\right)(Y-Z)}{k}-\frac{Y+\left(Y^{2}-4 k Z\right)^{\frac{1}{2}}}{2 k}>0$. Thus $b^{* *}$ increases with $\operatorname{var}(\mu)$.

\section{Case B.2}

When the reneging constraint binds we have,

$V\left(b, \beta^{* *}(b)\right)-w-t x=r b$ where $k=\frac{\operatorname{var}(\mu)}{1+\operatorname{var}(\mu)}$ 


$$
\begin{aligned}
& \text { or, } \frac{1}{4 \gamma}\left[2 b k-b^{2} k+1-k\right]-w-t x \geq r b \\
& \text { or }-k b^{2}+G b+H=0, \text { where } G=2 k-4 \gamma r \text { and } H=1-k-4 \gamma(w+t x)
\end{aligned}
$$

The solution to the optimization is the largest value of $b_{j} \in[0,1]$ that satisfies the quadratic equation,

yielding $b^{* *}=\frac{G+\left(G^{2}+4 k H\right)^{\frac{1}{2}}}{2 k}$

Since $G$ decreases with $r$, and $b^{* *}$ increases with $G, b^{* *}$ decreases with $r$. As $H$ decreases with $w$ and $t x$,and $b^{* *}$ increases with $H, b^{* *}$ decreases with $w$ and $t x$. And since $k$ increases with $\operatorname{var}(\mu), b^{* *}$ decreases with $\operatorname{var}(\mu)$.

Thus, $\frac{\partial b^{* *}}{\partial r}<0, \frac{\partial b^{* *}}{\partial w}<0, \frac{\partial b^{* *}}{\partial(t x)}<0$ and $\frac{\partial b^{* *}}{\partial v a r(\mu)}<0$. 


\section{References}

[1] Alchian, A. and Demsetz, H. (1972), "Production, Information Costs and Economic Organization," American Economic Review, 62: 777-795.

[2] Alesina, A. and La Ferrara, E. (2000), "Participation in Heterogeneous Communities," Quarterly Journal of Economics, 115(3): 847-904.

[3] Alesina, A. and Spolaore, E. (1997), "On the Number and Size of Nations," Quarterly Journal of Economics, November, pp. 1027-1056.

[4] Baker, G., Gibbons, R. and Murphy, K.J. (1994), "Subjective Performance Measures in Optimal Incentive Contracts," Quarterly Journal of Economics, 109: 1125-56.

[5] Baker, G., Gibbons, R. and Murphy, K.J. (1999), "Relational Contracts and the Theory of the Firm," Forthcoming in Quarterly Journal of Economics.

[6] Baker, G., Gibbons, R. and Murphy, K.J. (2001), "Bringing the Market Inside the Firm?," American Economic Review, 91 (2): 212-218.

[7] Berglof, E. and Perotti, E. (1994), "The governance structure of the Japanese financial keiretsu," Journal of Financial Economics, 36, pp. 259-284.

[8] Blanchard, O. and Kremer, M. (1997), "Disorganization," Quarterly Journal of Economics, 112 (4): 1091-1126.

[9] Chang, S.J. and Hong, J. (2000), "Economic Performance of Group-Affiliated Companies in Korea: Intragroup Resource Sharing and Internal Business Transactions," Academy of Management Journal, 43 (3): 429-448.

[10] Coase, R. (1937), "The Nature of the Firm," Economica, 4:386-405.

[11] Conner, K.R. and Prahalad, C.K. (1996), "A Resource-Based Theory of the Firm: Knowledge versus Opportunism," Organization Science, 7, 5: 477-501.

[12] Demsetz, H. (1993), "The Theory of the Firm Revisited," in Williamson, O.E. and Winter, S.G. edited The Nature of the Firm: Origins, Evolution and Development, Oxford University Press. 
[13] Ghatak, M. (2000), "Screening by the Company You Keep: Joint Liability Lending and the Peer Selection Effect." Economic Journal, Vol. 110, No. 465, pp. 601-631.

[14] Ghemawat, P. and Khanna, T. (1998), "The Nature of Diversified Business Groups: A Research Design and Two Case Studies," Journal of Industrial Economics, Volume 66, No. 1. pp. 35-61.

[15] Granovetter, M. (1995), "Coase Revisited: Business Groups in the Modern Economy," Industrial and Corporate Change, 4 (1): 93-130.

[16] Grossman, G. E. and Helpman, E. (2001), "Integration vs. Outsourcing in Industry Equilibrium," Forthcoming in Quarterly Journal of Economics.

[17] Grossman, S. and Hart, O. (1986), "The Costs and Benefits of Ownership: A Theory of Lateral and Vertical Integration," Journal of Political Economy, 94: 691-719.

[18] Guillen, M. (2000), "Business Groups in Emerging Economies: A Resource-Based View," Academy of Management Journal, 43 (3): 362-380.

[19] Hamel, G. and Prahalad, C.K. (1990), "The Core Competence of the Corporation," Harvard Business Review, May-June: 79-90.

[20] Hart, O. and Moore, J. (1990), "Property Rights and the Nature of the Firm," Journal of Political Economy, 98: 1119-1158.

[21] Holmstrom, B. and Milgrom, P. (1994), "The Firm as an Incentive System," American Economic Review, 84: 972-991.

[22] Holmstrom, B. and Roberts, J. (1998), "The Boundaries of the Firm Revisited," Journal of Economic Perspectives, 12: 73-94.

[23] Holmstrom, B. (1999), "The Firm as a Subeconomy," Journal of Law, Economics and Organization, 15(1): 74-102.

[24] Kali, R. (1999), "Endogenous Business Networks," Journal of Law, Economics and Organization. October 1999. pp. 615-636. 
[25] Khanna, T. and Palepu, K. (1999a), "Policy Shocks, Market Intermediaries, and Corporate Strategy: The Evolution of Business Groups in Chile and India," Journal of Economics and Management Strategy, Vol. 8, No. 2. pp. 271-310.

[26] Khanna, T. and Rivkin, J. (1999b) "Estimating the Performance Effects of Networks in Emerging Markets," Academy of Management Best Paper Proceedings 1999.

[27] Khanna, T. and Palepu, K. (1999c), "The Future of Business Groups in Emerging Markets: Long Run Evidence from Chile," Forthcoming, Academy of Management Journal

[28] Khanna, T. and J.W. Rivkin (2000), "Ties that bind business groups : Evidence from Chile." Mimeo. Harvard Business School.

[29] Keister, L. (2000), Chinese Business Groups: The Structure and Impact of Interfirm Relations during Economic Development, Oxford University Press.

[30] La Porta, R., Lopez-De-Silanes, F. and Shleifer, A. (1999), "Corporate Ownership Around the World," Journal of Finance, Vol. 54, No. 2, pp. 471-517.

[31] McMillan, J. and Woodruff, C. (1999), "Interfirm Relationships and Informal Credit in Vietnam," Quarterly Journal of Economics, 114: 1285-1320.

[32] McMillan, J. and Woodruff, C. (1999), "Dispute Prevention Without Courts in Vietnam," Journal of Law, Economics and Organization, Vol. 15, No. 4: 637-658

[33] Montgomery, C. (1994), "Corporate Diversification," Journal of Economic Perspectives, 8 (3):163-178.

[34] Penrose, E. (1959), The Theory of the Growth of the Firm, Basil Blackwell.

[35] Perotti, E. and S. Gelfer (1999), "Red Barons or Robber Barons? Governance and Financing in Russian Financial-Industrial Groups", Mimeo, University of Amsterdam.

[36] Rajan, R. and Zingales, Z. (1998), "Power in a Theory of the Firm," Quarterly Journal of Economics, 113: 387-432. 
[37] Rajan, R. and Zingales, Z. (2001), "The Firm as a Dedicated Hierarchy: A Theory of the Origin and Growth of Firms," Quarterly Journal of Economics, 116: 805-851.

[38] Recanatini, F. and Ryterman, R. (2000), "Disorganization or Self-Organization" Mimeo, The World Bank.

[39] Simon, H. (1951), "A Formal Theory of the Employment Relationship," Econometrica, 19: 293-305.

[40] Stiglitz, J. (1999), "Corporate Governance Failures in the Transition," Keynote Address, Annual Bank Conference on Development Economics-Europe, Paris June 21-23.

[41] Teece, D. J., Rumelt, R., Dosi, G. and Winter, S. (1994), "Understanding Corporate Coherence: Theory and Evidence." Journal of Economic Behavior and Organization, 23: $1-30$.

[42] Wernerfelt, B. (1984), "A Resource Based View of the Firm," Strategic Management Journal, 5: 171-180.

[43] Williamson, O.E. (1975), Markets and Hierarchies: Analysis and Antitrust Implications, New York, Free Press.

[44] Williamson, O.E. (1985), The Economic Institutions of Capitalism, New York, Free Press.

[45] Zingales, Z. (2000), "In Search of New Foundations," Journal of Finance, 55(4): 1623 1653. 